\title{
Avokado Odununun Bazı Kimyasal ve Morfolojik Özelliklerinin Belirlenmesi ve Kağıt Hamuru Üretimine Uygunluğunun Araştırılması
}

\author{
Gülşah ALTUNIŞIK BÜLBÜL, Ayhan GENÇER ${ }^{1 *}$ \\ ${ }^{1}$ Bartın Üniversitesi, Orman Fakültesi, Orman Endüstri Mühendisliği Bölümü,74100, BARTIN
}

Öz

Bu çalışmada avokado (Persea americana Mill.) odunun bazı kimyasal ve morfolojik özellikleri belirlenmiştir. Avokado odunun temel kimyasal bileşenleri holoselüloz, $\alpha$-selüloz ve lignin sırasıly \% $\% 3.29,55.05$ ve 14.85 olarak tespit edilmiştir. Sicak su, soğuksu, alkol ve \%1 NaOH çözünürlük değerleri ise sırasılla \%2.64, 1.51, 4.5, 19.75 bulunmuştur. Kağıt hamuru üretiminde, özellikle kimyasal yöntem kullanıldığında, yüksek $\alpha$-selüloz ve düşük lignin oranı önemlidir. Sonuçlara göre avokado odunun kimyasal bileşenleri bakımından mevcut meyve ağaçları ve bazı yapraklı ağaç odunları ile benzer özelliklerdedir. Lignoselülozik bir hammaddeden kağıt üretiminde lif morfolojisi önemli olup, kağıdın temel sağlamlık özelliklerini belirlemektedir. Avokado odunun lifleri orta uzunlukta olup, literatürde bulunan bazı meyve ağaçları ve kağıt hamuru üretiminde kullanılan yapraklı ağaç odunlarının lifleri ile benzer özellikte olduğu görülmektedir. Buna göre avokado odunu kağıt hamuru üretiminde kullanılabilecek özelliktedir.

Anahtar Kelimeler: Avokado (Persea americana Mill.) odunu, Morfolojik özellikler, Kimyasal özellikler, Kağıt hamuru

\section{Determination of Some Chemical and Morphological Properties of Avocado Wood and Researching Its Suitability for Pulp Production}

\begin{abstract}
In this study some chemical and morphological properties of avocado (Persea americana Mill.) wood have been studied. The main chemical constituents of avocado wood holocellulose, $\alpha$-cellulose and lignin were determined as $73.29 \%, 55.05$ and $14.85 \%$, respectively. High $\alpha$-cellulose and low lignin ratios are important in pulp production, especially when chemical method is used. Hot water, cold water, alcohol and $1 \% \mathrm{NaOH}$ solubility values were found to be $2.64 \%, 1.51,4.5,19.75$, respectively. According to the results, avocado wood is found close to other fruit trees and some hardwood species in terms of chemical components of wood. In the production of paper from a lignocellulosic raw material, fiber morphology is important and determines the basic strength properties of the paper. The fibers of avocado wood are of medium length, and it is seen that the fibers of some fruit trees and woods used in pulp production are similar to the fibers presented in previous studies. Thus, avocado wood can be used in pulp production.
\end{abstract}

Keywords:.Avocado (Persea americana Mill.) wood, Morphological properties, Chemical properties, Paper pulp 


\section{Giriş}

Odunun yapısı karmaşık, ama birbiri ile bağlantısı olan hücre ve dokulardan oluşmuştur. Bu karmaşık yapı içerisinde bulunan hücrelerin her birinin görevi farklıdır. Ağaç, hayat faaliyetlerini bu görev bölüşümü sayesinde yerine getirirken her yıl yeni odun dokusu oluşturur. Yeni odun dokusu oluşurken kambiyum hücreleri bitkinin hayatı boyunca belirli zamanlarda bölünerek sekonder floem (kabuk) ve sekonder ksilem (odun) gövdeye ilave ederek çap yönünde büyümeyi (çap artımı) sağlar (Merev, 2003). Bu bölünme ile kambiyumda farklı hücreler meydana gelmektedir. Bunlardan, paranşim hücreleri su ve besin depolamakla görevlidir. Lifler destek elemanlarıdır ve odunun yapısına katılığı verirler. Traheitler ve traheler su iletimi ve mekanik destek elemanlarıdır. Bu hücrelerin odunda bulunuşu ve oranları, odunun yapraklı ağaç (YA) odunu veya iğne yapraklı ağaç (IYYA) odunu olmasına göre değişiklik göstermektedir. Traheit ve libriform lifleri ağaç boyuna yönünde uzanmış boyları çaplarının 50-100 katı kadar uzun olan hücrelerdir. İYA traheitleri 1-11mm arasında olup, ticari önemi olan ağaçlarda 2-5 mm dir. YA libriform lifleri kısa olup, 1-2 mm civarındadır. Trahe hücreleri geniş, kısa ve ince çeperlidir. Çapları 20-500 $\mu \mathrm{m}$ arasında olabilir. Boyları oldukça değişken olup geniş varyasyonludur. Paranşim hücreleri genellikle küçük olup boyları 20-200 $\mu \mathrm{m}$ arasındadır. Kağıt üretimi bakımından, bu hücreler arasında traheit ve libriform liflerinin boyutları ve oduna katılım oranları diğerlerinden daha fazla önemlidir. Çünkü, kağıt safihasının çok önemli bir kısmı IYYA odunlarının traheit liflerinden, YA odunlarının libriform liflerinden oluşmaktadır (Rydholm, 1965).

Kağıt üretiminde hammadde olarak odunun, orman ağacı, meyve ağacı, çalı veya süs bitkisi olması önemli değildir. Çünkü odun oluşumu için gerekli üç ana bileşen selüloz, hemiselülozlar ve lignin odunsu bitkilerin hepsinde mevcuttur. Bu nedenle odunun yapısı hemen odunsu bitkilerin hepsinde aynı olup, sadece bazı oranlarda değişiklikler mevcuttur. Kağıt hamurun kalitesini belirleyen faktörler odun liflerinin morfolojik özellikleri ve odunun kimyasal bileşenleridir. Başka bir ifade ile hammaddenin kaynağı değil, teknik özelliklerinin uygunluğu esastır. Ayrıca, ekonomik olarak kullanılabilmesi için yeterli miktarda olması gerekir. Bu durumda orman ağaçları ve plantasyon ormanları öne çıkmaktadır. Ancak, dünyanın artan gıda ihtiyacı dolayısıyla meyve bahçeleri profesyonel bir yaklaşımla oldukça geniş alanlara yayılmaktadır. Artan nüfusa oranla bu alanlar da artacaktır. Meyve bahçelerinde bakım ve gençleştirme aşamalarında önemli bir odun hammaddesi arzı oluşmaktadır. Bu nedenle, endüstriyel kullanımda meyve odunlarına talep artmaktadır. Örneğin, bir çalışmada 100 ha elma bahçesinde her yıl yapılan bahçe bakımından geriye kalan budama artıklarının yakılarak enerjiye dönüştürülmesi durumunda 10 yılda elde edilen toplam gelirin net bu günkü değeri (Net Present Value) €5644 olduğu belirtilmiştir (Dyjakon vd., 2020). Kayısı odununun bazı fiziksel ve mekanik özelliklerinin incelendiği bir çalışmanın sonucuna göre mobilya üretiminde kullanılabileceği belirtilmiştir (Çavuş, 2020). Gül odunundan yapılan bir çalışmada kimyasal özelliklerinin kağıt hamuru üretiminde kullanılan odun türlerine benzerlik gösterdiği ve lif özelliklerinin de kağıt üretimine uygun olduğu belirtilmiştir (Özcan ve Dönmez 2018). Diğer bir çalışmada ise biberiye saplarının kimyasal özelliklerinin YA özelliği gösterdiği ancak liflerinin kağıt üretimine uygun olmadığı ve kompozit levha üretiminde kullanılması önerilmiştir (Odabaş Serin vd., 2017). Bazı asli orman ağaçlarının lifleri, çeşitli tarım artıkları ve fındık kabuğu kullanılan bir çalışmada fındık kabuğunun MDF üretiminde alternatif hammadde olabileceği belirtilmiştir (Akgül vd., 2017). Hırnık, zeytin ve yenidünya ağaçları gövde odunlarının hava kurusu yoğunluk değerleri bakımından "ağır ağaçlar" sınıfında yer aldığı, yüksek yoğunluk değerlerine sahip her üç meyve ağacının gövde odunlarının tornacılıkta, oymacılıkta ve oyuncak üretiminde ve diğer orman endüstri sanayisinde artan hammadde ihtiyacına alternatif olabileceği sonucuna varılmıştır (Topaloğlu vd., 2019).

Kağıt liflerin su maharetiyle bir elek üzerinde bir araya gelerek oluşturdukları yaş safihanın kurutulması sonucu oluşan bir malzemedir (Eroğlu, 1990). Bu safihanın oluşabilmesi ve süzülüp kurutulması için belli bir lif uzunluğu gereklidir. Kağıt sağlamlığı, özellikle yırtılma direnci liflerin kendi aralarında yaptıkları bağların sayısı ve lif uzunluğu ile doğru orantılıdır. Ancak, kağıdın sağlamlık özelliklerini sadece lif uzunluğu ile ilişkilendirmek yanıltıcı olur. Çünkü, safiha oluşumu sırasında lif genişliği ve çeper kalınlığının oransal ilişkisine bağlı olarak bağ oluşumu değişmektedir. Bu oransal ilişki kağıdın fiziksel ve mekanik özelliklerini önemli ölçüde etkilemektedir.

Kağıt formasyonu oluşturan hidrojen bağlarının oluşması için liflerin belirli bir mesafeye kadar bir birlerine yaklaşmaları şarttır. Bu durum Şekil 1'de enine kesitleri temsili olarak çizilen lif resimlerinde gösterilmiştir. Şekil 1'de aynı lif genişliğinde (R) olduğu var sayılan A ve B liflerinin lümen çapları (a, b) ve çeper kalınlıkları (x, y) farklı alınmıştır. İnce çeperli lifler (A) delignifikasyon sırasında yassılaşarak kurdele şeklini alırken (A*) bir birine yaklaşan liflerin temas alanı artar. Buna bağlı olarak bağ sayısı ve kağıdın sağlamlığı da artmaktadır. Kalın çeperli lifler (B) ise yassılaşmayıp veya çok az yassılaşıp $(B *)$ silindirin teğet değme noktası kadar bir bağlanma alanı oluştururlar. Bu durumda temas alanı ve bağ sayısı az olur buna bağlı olarak da kağıdın sağlamlığı azalmaktadır. 


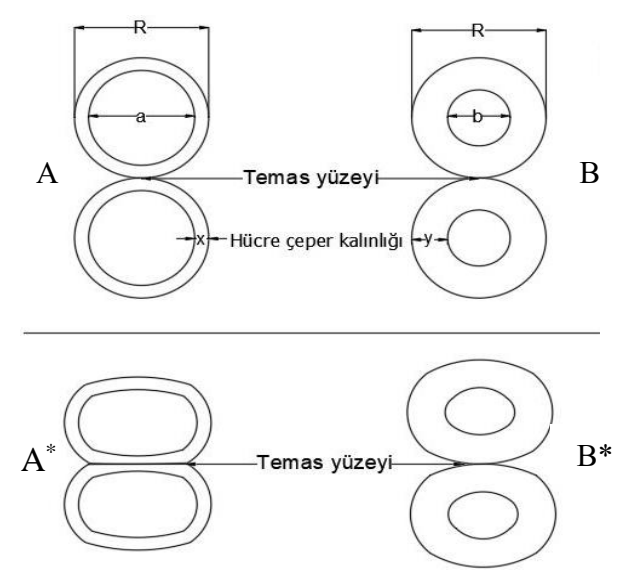

Şekil 1. Liflerin kağıt safihası oluştururken enine kesitlerindeki temasın temsili resmedilmesi

Çok ince çeperli liflerin kullanılması sonucu temas alanı ve bağ sayısı artarken çok yüksek yırtılma direnci beklenmemelidir. Çünkü yırtılma bağ sayısından bağımsız olarak çeperden olabilir. Bu durum çok kalın liflerde de yırtılma yerine çıkma şeklinde olup, yırtılma direncini düşürmektedir. $\mathrm{Bu}$ nedenlerle çoğunlukla liflerin morfolojik özellikleri ve kağıdın sağlamlığı arasında doğrusal bir ilişki kurulamaz. Bu nedenlerle üretilecek kağıdın özelliklerine uygun hammadde seçilmelidir. Bu yüzden mevcut potansiyel odun kaynaklarının kimyasal ve morfolojik özelliklerinin bilinmesi önemlidir.

Avokado (Persea americana Mill.) Lauraceae familyasına aittir. Yetiştiriciliği yapılan bakımlı bahçelerde 10-15 $\mathrm{m}$ boy ve 40-60 cm çap yapması meyve verimi açısından ideal kabul edilmektedir. Doğal ortamda karışık meşcerelerde 25-30 m uzunlukta olabilir. Meksika ve Orta Amerika’ya özgü bir tür olmakla beraber daha çok Akdeniz iklimi gösteren birçok ülkede yaygın olarak yetiştirilen türleri mevcuttur. Ülkemizde Akdeniz Bölgesi'nde yetiştiriciliği yapılmaktadır (Demirkol, 2001; Bayram vd., 2006). Hemen hemen Güney Amerika kıtasının tamamında üretimi yapılmakla beraber, İspanya, Afrika, Avustralya, Yeni Zelanda ve Küba'da geniş üretim sahaları mevcuttur (Zentymer, 1987). Avokado dal odunu hava kurusu özgül ağırlığının (0,44-0,54-0,64 $\mathrm{g} / \mathrm{cm}^{3}$ ) düşükten orta yoğunluğa değiştiği belirtilmiştir (Fuentes-Talavera vd., 2011). Bu özellikteki odunlar orta yoğunlukta olup, esnek liflidirler (Kırc1, 2000) kağıt hamuru üretiminde değerlendirilebilirler. Ayrıca, bu çalışmada ülkemizde yetiştirilen çeşitli meyve ağacı odunlarının ve endüstriyel öneme sahip yaygın türlerin bazı kimyasal ve anatomik özellikleri hakkında literatür çalışması yapılmıştır. Çalışma konusu olan avokado odununun kimyasal ve morfolojik özellikleri tespit edilerek, literatürle karşılaştırılmıştır.

\section{Materyal ve Metot}

\subsection{Materyal}

Bu çalışmada kullanılan odun örneği Antalya ili Gazipaşa ilçesinde 4-5 m rakımda meyve üretimi yapılan bir bahçeden sıklık bakımı sırasında, faydalı ömrünü tamamladığı için kesilen 15 yaşındaki avokado (Persea americana Mill.) ağaçlarının ana gövdesinden alınmıştır. Maserasyon işleminde saf su, sodyum klorit $\left(\mathrm{NaClO}_{2}\right)$ ve asetik asit $\left(\mathrm{CH}_{3} \mathrm{COOH}\right)$ kullanılmıştır. Kalıcı preparatlar gliserin kullanılarak hazırlanmıştır.

\subsection{Metot}

Morfolojik ölçümlerin yapılması amacıyla kibrit çöpü ölçülerine benzer şekilde yongalanan avokado odunu örnekleri maserasyon yöntemi (Wise ve Jahn, 1952) ile bireysel lifler haline getirilmiştir. Bu liflerden rastgele örnek alınarak kalıcı preparatlar hazırlanmıştır. Işık mikroskobu altında incelen preparatlardan çekilen fotoğraflar Şekil 2'de görünmektedir. Bu preparatlardan yapılan lif ölçümlerinden avokado odununun Elastiklik Oranı, Runkel Sınıflandırması, Keçeleşme Oranı ve Katılık Katsayısı aşağıda belirtilen formüllerle hesaplanmıştır.

Elastiklik Oranı $=($ Lümen Çapı x 100) / Lif Genişliği

Runkel Sınıflandırması $=($ Lif çeper Kalınlığı x 2) / Lümen Çapı

Keçeleşme Oranı = Lif Uzunluğu / Lif Genişliği (Kırc1, 2000)

Katılık Katsayısı = (Lif Çeper Kalınlığı x 100)/ Lif Genişliği (Eroğlu, 2003)

Kimyasal özellikleri belirlemek için odun örnekleri TAPPI T 264 cm-07 (2007)'e göre kibrit çöpü şeklinde hazırlanıp Willey değirmende odun unu haline getirilmiştir. Odun unu sarsıntılı elekte sirasıyla 40-60-80 mesh'lik 
eleklerde elenmiş ve 60 mesh'lik elekte kalan örnekler kimyasal analizlerde kullanılmıştır. Holoselüloz tayini Klorit (Wise ve Jahn, 1952), $\alpha$-selüloz tayini Rowell (2005), lignin tayini TAPPI T 222 om-02 göre \% olarak hesaplanmıştır. Alkol çözünürlüğü TAPPI T 204 cm-97, soğuk ve sıcak su çözünürlükleri TAPPI T 207 cm-99 ve \%1'lik NaOH çözünürlüğü TAPPI T 212 om-02 standardına göre yapılmıştır.

\section{Bulgular ve Tartışma}

Morfolojik değerlendirmede avokado odunun maserasyonundan elde edilen liflerden oluşturulan kalıcı preparatlar edilen bazı morfolojik özellikler ve bunlardan türetilen değerlerden faydalanılmıştır. Avokado odunundan elde edilen kalıcı preparatlar Şekil 2'de görülmektedir.

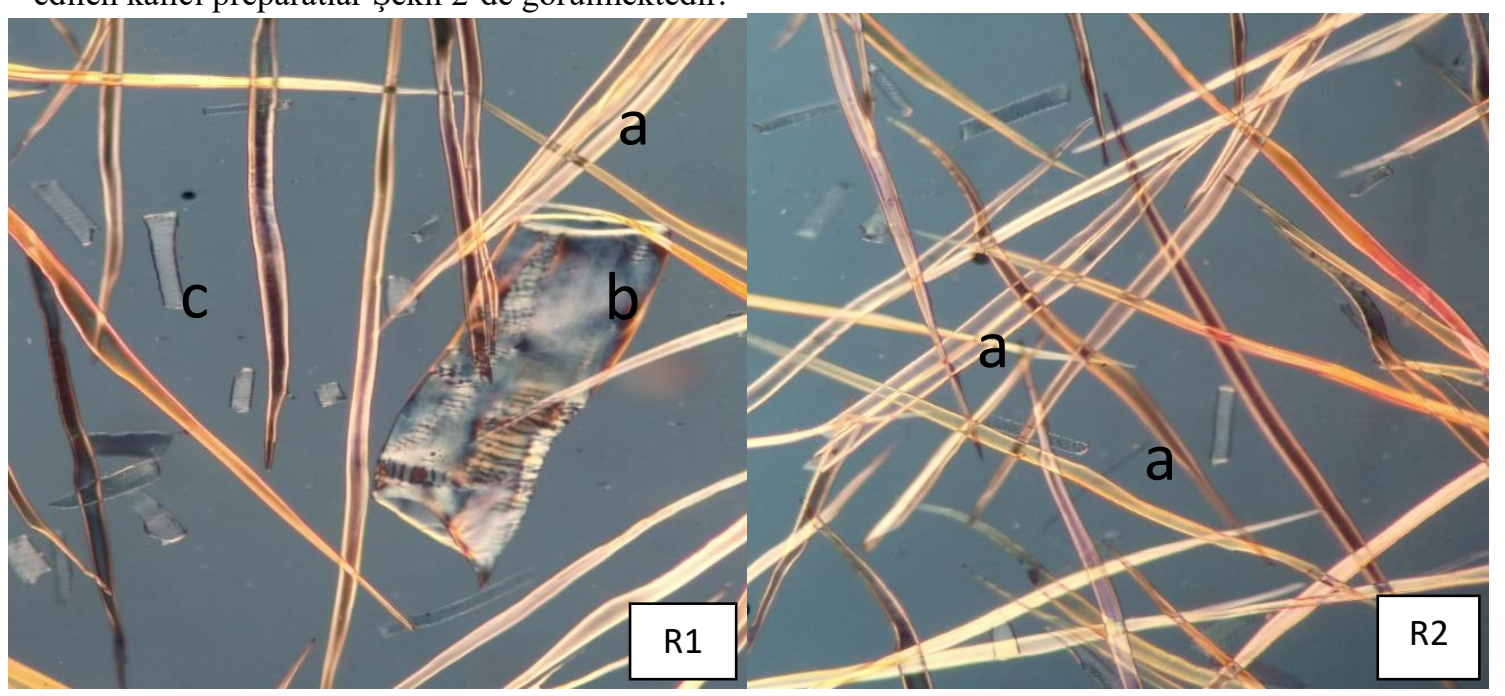

Şekil 2 Avokado (Persea americana Mill.) odunundan hazırlanmış prepratların ışık mikroskobu yardımı ile görünüşü (: a libriform lifi, b: Trahe hücresi, c: Paranşim hücresi, Altunış1k Bülbül 2019)

Hamur kalitesine etkilerinden dolayı libriform liflerinin oduna katılma oranı önemlidir. Şekil 2 (R1-R2) de avokado odunundan rastgele hazırlanmış kalıcı preparatlardan 1 şı mikroskobu yardımı ile fotoğraflanmış hücreler görülmektedir. Şekilde, kağıt hamuru veriminde etkili olan libriform liflerinin sayısal çoğunluğu dikkat çekmektedir.

Tablo 1'de avokado odunun ölçülen lif boyutları ve bunlardan türetilmiş değerler görülmektedir.

Tablo 1 Avokado odununun lif boyutları ve bunlardan türetilen değerler

\begin{tabular}{lclll}
\hline & Lif Boyutları & & \multicolumn{2}{c}{ Türetilen Değerler } \\
\hline Lif Uzunluğu & $(\mathrm{mm})$ & 1,06 & Elastiklik Katsayısı & 63,0 \\
\hline Lif Genişliği & $(\mu \mathrm{m})$ & 25,78 & Katılık Katsayısı & 19,0 \\
\hline Lümen Genişliği & $(\mu \mathrm{m})$ & 16,18 & Runkel Oranı & 0,59 \\
\hline Çeper Kalınlığı & $(\mu \mathrm{m})$ & 4,80 & Keçeleşme Oranı & 41,0 \\
\hline
\end{tabular}

Tablo 1'de avokado odununa ait lif uzunluğu, lif genişliği lümen genişliği ve çeper kalınlığı sırasıyla 1,06 mm, 25,78, 16,18, 4,80 $\mu \mathrm{m}$ dir. Avokado odununun Elastiklik Katsayısı, Katılık Katsayısı, Runkel Oranı ve Keçeleşme Oranı sırasıyla 63,0, 19,0, 0,59 ve 41,0 olarak belirlenmiştir. Elastiklik Katsayısı 50-75 arasında olan lifler çeper kalınlıkları biraz fazla olmasına karşın lümenleri geniş olduğundan direnç özellikleri iyi olan kâğıtlar verirler. Runkel Oranı 1'den küçük olan lifler kağıt yapımında kolayca yassılaşarak yüksek oranda bağ alanı oluştururlar. YA odunu liflerinin Keçeleşme Oranı 70'in altındadır. Bu oranın düşmesi kağıdın direnç özelliklerinin düşmesi anlamına gelir (Kırcı,2000). Katılık katsayısının artması ile kâğıdın kopma ve patlama dirençleri azalmaktadır (Eroğlu, 2003). Tablo 1'deki türetilen değerlere göre avokado odunundan düzgün yüzeyli yazı baskı kağıtları elde edilebilir. Tablo 2'de avokado odunun lif boyutlarının bazı meyve ağaçları ve endüstriyel ağaçlarla karşılaştırılması yapılmıştır. 
Tablo 2. Avokado odunun lif boyutlarının bazı meyve ağaçları ve endüstriyel ağaçlarla karşılaştırılması

\begin{tabular}{|c|c|c|c|c|c|c|}
\hline Odun türü & $\begin{array}{l}\text { Lif U. } \\
(\mathrm{mm})\end{array}$ & $\begin{array}{c}\text { Lif G. } \\
(\mu \mathrm{m})\end{array}$ & $\begin{array}{l}\text { Lümen G. } \\
\qquad(\mu \mathrm{m})\end{array}$ & $\begin{array}{c}\text { Çeper K. } \\
(\mu \mathrm{m})\end{array}$ & Yöre & Kaynak \\
\hline Avokado & 1,06 & 25,78 & 16,18 & 4,80 & Antalya & Tespit \\
\hline Avokado & 0,97 & 35,60 & 21,30 & 7,20 & - & Silva vd., 1994 \\
\hline Dişbudak & 1,15 & 24,60 & 14,90 & 3,60 & - & Güler ve ark., 2012 \\
\hline Hirnık & 0,94 & 16,59 & 6,17 & 5,21 & Artvin & Topaloğlu vd., 2019 \\
\hline İncir & 0,83 & 22,05 & 16,05 & 5,44 & Aydın & Odabaş Serin ve Kılıç \\
\hline İncir & 0,88 & 20,44 & 16,58 & 3,86 & K.Maraş & Penezoğlu 2020a \\
\hline İncir & 0,95 & 21,40 & 12,50 & 4,50 & Batı Karadeniz & Yaman, 2014 \\
\hline Kara dut & 1,28 & 23,00 & 14,20 & 3,60 & Hindistan & Walia, 2013 \\
\hline Kay1s1 & 0,70 & 12,91 & 5,87 & 3,52 & Malatya & Gençer vd., 2018 \\
\hline Kivi & 1,59 & 35,97 & 22,30 & 6,84 & Trabzon & Yaman ve Gençer, 2005 \\
\hline K1zılağaç & 1,20 & 26,46 & 17,32 & 4,57 & Trabzon & Tirak Hizal ve Erdin 2016 \\
\hline Lemas limonu & 0,75 & 13,74 & 6,36 & 3,69 & Mersin & Tutuş vd., 2018 \\
\hline Nar & 0,74 & 20,95 & 11,65 & 4,65 & Antalya & Gulsoy vd., 2015 \\
\hline Titrek kavak & 1,10 & 23,90 & 11,40 & 6,30 & Bartın & Gulsoy ve Tüfek, 2013 \\
\hline $\begin{array}{l}\text { Trabzon } \\
\text { hurmas } 1\end{array}$ & 1,10 & 26,20 & 14,27 & 5,98 & Kahramanmaraş & Tutuş ve vd., 2014 \\
\hline Yabani kiraz & 0,96 & 19,35 & 11,26 & 4,04 & - & Yaman, 2002 \\
\hline Yabani kiraz & 1,10 & 19,70 & 10,43 & 4,64 & Bartın & Gençer ve Gül Türkmen, 2016 \\
\hline Yaygın findık & 1,04 & 22,20 & 13,66 & 4,30 & Bartın & Gençer ve Özgül, 2016 \\
\hline Yaygın findık & 1,06 & 23,80 & 14,08 & 4,80 & - & Merev, 1998 \\
\hline Yenidünya & 1,16 & 17,00 & 6,74 & 5,12 & Trabzon & Topaloğlu vd., 2019 \\
\hline Zeytin & 0,83 & 15,80 & 11,50 & 4,32 & Aydın & \multirow{2}{*}{$\begin{array}{l}\text { Odabaş Serin ve Kilıç } \\
\text { Penezoğlu 2020b }\end{array}$} \\
\hline Zeytin & 0,78 & 12,30 & 8,17 & 4,12 & Kahramanmaraş & \\
\hline Zeytin & 1,11 & 25,12 & 14,36 & 5,38 & Artvin & Topaloğlu vd., 2019 \\
\hline Ak meşe & 1,35 & 18,60 & 7,40 & 5,60 & Bartın & Gülsoy vd., 2005 \\
\hline Okaliptus & 0,69 & 20,78 & 6,42 & 7,18 & Mersin & Gürboy ve Özden 1994 \\
\hline
\end{tabular}

U:Uzunluğu, G: Genişliği, K:Kalınlığı

Kağıt hamuru üretimi bakımından liflerin en önemli morfolojik özelliklerinden biri lif uzunluğudur. IAWA (1989)'a göre lif uzunluğu 0,90-1,60 mm arasında olan odunlar orta uzunluğa sahiptir. Avokado odunun lif uzunluğu 1,06 mm'dir ve orta uzunluktaki lif sınıfına dahildir. Bu lif grubu hem uzun lif hem kısa liflerin yerine kullanılabildiği için kâğıt üretimi açısından ayrı bir önem arz etmektedir. Eroğlu (1990) çok uzun liflerin kâğıt üretimi sırasında topaklanma yaptığını, çok kısa liflerin ise elekte süzülme problemine neden olduğunu belirtmiştir. Topaklanma kağıtta formasyon bozukluğuna ve homojen yapının bozulmasına sebep olur. Bu durumda kağıtta mekanik kayıplar meydana gelmektedir. Çok kısa liflerden elde edilen kağıtların ise mekanik dirençlerinin zayıf olduğu bilinmektedir. Tablo 2'deki çeşitli meyve ağaçları ve endüstriyel öneme sahip bazı ağaç türlerinin lif uzunluklarının ortalaması 1,01 olup avokado odunun lif uzunluğu ortalama değere yakın olması dikkat çekmektedir. Bu durumda avokado odunu morfolojik kağıt üretimi bakımından Tablo 2'deki türler ile rekabet edebilir. Tablo 3’te avokado odunun bazı kimyasal bileşenleri ve çözünürlük oranları görülmektedir.

Tablo 3. Avokado odununu kimyasal bileşenleri ve bazı çözünürlük değerleri

\begin{tabular}{llll}
\hline \multicolumn{2}{l}{ Kimyasal Bileşenler (\%) } & \multicolumn{2}{l}{ Çözünürlük Değerleri (\%) } \\
\hline Holoselüloz & 73,29 & Sicak su & 2,64 \\
\hline Hemiselülozlar & 15,12 & Soğuk su & 1,51 \\
\hline$\alpha$-selüloz & 55,05 & Alkol & 4,50 \\
\hline Lignin & 14,85 & $\% 1 \mathrm{NaOH}$ & 19,75 \\
\hline
\end{tabular}

Odunun temel bileşenlerini holoselüloz ve lignin oluşturmaktadır. Holoselüloz, odundan ligninin uzaklaştırılmasından sonra geriye kalan toplam karbonhidrattır. Kimyasal yöntemle üretilmiş bir hamurdan elde edilen kağıdın en önemli bileşeni $\alpha$-selülozdur. Kullanılan kağıt hamuru yöntemine ve bu yöntemdeki pişirme 
şartlarına göre hamurda kalan karbonhidrat miktarı değişmektedir (Casey, 1960). Kimyasal yöntemlerde kağıt hamuru üretiminde $\alpha$-selüloz oranı yüksek türler kullanılması hamur verimini de arttırmaktadır.

Lignin odunun temel bileşenlerinden biridir. Ancak, yapısı YA ve IYYA da farklı olmakla birlikte, aynı ağaç türünde de izole edildiği yönteme göre farklılıklar göstermektedir. Odun hücrelerini birbirine bağlayan orta lamel ve primer çeperin ana bağlayıcı maddesidir. Lignin orta lamelde mikrofibrilleri içinde barındırırken, ağırlıkça orta lamelin \%71 ini oluşturur. Buradan fibrillerin içine doğru penetre olarak primer çeperden sekonder tabakada miseller arası boşlukları doldurarak S1-S2-S3 tabakasına doğru oransal olarak azalarak yayılır (Casey, 1960). Lignin, liflerin birbirine bağlanarak odunu oluşturmasında çimento görevi yapmaktadır. Odunun lignin oranı yükseldikçe kimyasal yöntemlerle kağıt hamuru üretiminde delignifikasyon işleminde kimyasal madde sarfiyatı da yükselmektedir. Avokado oduna ait holoselüloz, $\alpha$-selüloz ve lignin oranları, ekstraktif madde ve $\% 1 \mathrm{NaOH}$ çözünürlüğü literatürdeki bazı meyve ağaçları ve endüstriyel ağaçlarla karşılaştırılarak Tablo 4'de verilmiştir.

Tablo 4. Avokado odunun bazı kimyasal bileşenleri ve çözünürlük değerlerinin bazı meyve ağaçları ve endüstriyel ağaçlarla karşılaştırılması

\begin{tabular}{|c|c|c|c|c|c|c|c|}
\hline Odun türü & $\begin{array}{c}\mathrm{H} \\
(\%)\end{array}$ & $\begin{array}{l}\alpha \text {-selüloz } \\
\text { /selüloz* }\end{array}$ & $\begin{array}{l}\text { Lignin } \\
(\%)\end{array}$ & $\begin{array}{l}\text { E. } \\
(\%)\end{array}$ & $\begin{array}{l}\% 1 \\
\text { A.Ç. }\end{array}$ & Yöre & Kaynak \\
\hline Avokado & 73,29 & 55,05 & 14,85 & 4,51 & 19,75 & Antalya & Tespit \\
\hline Ak meşe & 68,00 & $42,40 *$ & 24,50 & 6,60 & 22,30 & Bartın & Gülsoy vd., 2005 \\
\hline Ak dut & 85,90 & $53,08 *$ & 21,30 & 11,1 & 14,80 & Ankara & Gündüz vd., 2009 \\
\hline Armut & 76,10 & 37,90 & 22,80 & - & - & Karabük & Tümen, 1999 \\
\hline Ceviz & - & $40,80 *$ & 29,10 & 4,40 & - & - & As vd., 2001 \\
\hline Elma & 71,00 & - & 29,00 & 3,23 & 33,61 & Isparta & Şahin ve Arslan, 2013 \\
\hline$\dot{\mathrm{I}} \breve{g d e}{ }^{\circ}$ & 81,50 & 51,30 & 23,05 & 39,5 & 14,40 & Balıkesir & Akgül ve Akça, 2014॰ \\
\hline İncir & 72,20 & 38,47 & 22,71 & 1,00 & 19,62 & Aydın & Odabaş Serin ve Kılıç \\
\hline İncir & 64,43 & 41,78 & 16,18 & 7,92 & 24,53 & Kahramanmaraş & Penezoğlu, 2020a \\
\hline Kara dut & 69,15 & 45,00 & 21,42 & 2,60 & 18,00 & Hindistan & Walia, 2013 \\
\hline Kay1s1 & 80,06 & $49,50 *$ & 30,03 & 5,88 & 27,40 & Malatya & Tutuş vd., 2016a \\
\hline Kay1s1 & 79,50 & 42,33 & 16,43 & 9,32 & - & Malatya & Gençer vd., 2018 \\
\hline Kiwi & - & $38,38 *$ & 26,27 & 6,24 & 41,62 & Karadeniz & Nemli, 2003 \\
\hline $\begin{array}{l}\text { Lemas } \\
\text { limonu }\end{array}$ & 83,17 & 47,36 & 23,92 & 1,23 & 14,40 & Mersin & Tutuş vd., 2016b \\
\hline Nar & 73,50 & 39,92 & 25,90 & 2,53 & - & Antalya & Gulsoy ve ark., 2015 \\
\hline Portakal & 80,50 & 50,70 & 20,80 & 13,7 & 14,30 & Mersin & Kesik vd., 2017 \\
\hline Söğüt & 89,20 & $49,00 *$ & 23,20 & 3,20 & - & - & As vd., 2001 \\
\hline Titrek kavak & 82,68 & 49,03 & 16,69 & 3,22 & 15,34 & Bartın & Gülsoy vd., 2013 \\
\hline $\begin{array}{l}\text { Trabzon } \\
\text { hurmas1 }\end{array}$ & 70,80 & 36,45 & 29,82 & - & 13,27 & Kahramanmaraş & Tutuş vd., 2014 \\
\hline Turunç & 81,18 & 48,84 & 19,73 & 7,94 & 14,92 & Akdeniz & Tutuş vd., 2016 \\
\hline Yabani kiraz & 77,20 & 39,65 & 17,00 & 8,55 & 25,15 & Bartın & $\begin{array}{l}\text { Gençer ve Gül Türkmen, } \\
2016\end{array}$ \\
\hline Yaygın findık & 82,07 & 41,33 & 15,89 & 2,83 & 18,48 & Bartın & Gençer ve Özgül, 2016 \\
\hline Zeytin & 70,40 & 39,80 & 25,00 & 4,88 & 20,40 & Aydın & Odabaş Serin ve Kılıç \\
\hline Zeytin & 58,60 & 36,00 & 25,30 & 17,0 & 28,30 & Kahramanmaraş & Penezoğlu, 2020b \\
\hline
\end{tabular}

H: Holoselüloz, E: Ekstraktif madde, \%1 A.Ç.: \%1 NaOH Çözünürlüğü, (॰): Kaynağında alt-üst değer şeklinde yazılmış olup burada aritmetik ortalama hesaplanarak yazılmıştır. Not: Bu çalışmada ekstraktif madde miktarı alkol çözünürlüğü ile tayin edilmiştir. Ekstraktif madde tayininde Tablo 4’teki kaynaklardan bazıları alkol bazıları ise farklı çözücüler kullanmış olup, tabloda belirtilmemiştir.

Tablo 4'te yer alan meyve ağaçları ve endüstriyel kullanımı yaygın olan bazı türlerle karşılaştırıldığında avokado odunun $\alpha$-selüloz oranı en yüksek, lignin oranı en düşük değeri almaktadır. Kimyasal yöntemlerle kağıt hamuru üretiminde $\alpha$-selüloz oranı yüksek olması hamur verimine olumlu katkı sağlamaktadır. Lignin oranının düşük olması kimyasal yöntemlerle kağıt hamuru üretiminde delignifikasyon işleminde kimyasal madde tüketimi ve enerji sarfiyatı bakımından bir avantajdır. Bu özellikleri ile avokado odunu kimyasal yöntemlerle kağıt hamuru üretimine uygundur. 


\section{Sonuç ve Öneriler}

Bu çalışmada avokado odunun bazı morfolojik ve kimyasal özellikleri belirlenerek, kağıt hamuru üretimine uygunluğu hakkında ön fikir edinilmeye çalışılmıştır. Sonuçların karşılaştırılması için diğer meyve ağaçları odunlarının bazı kimyasal ve morfolojik özellikleri literatürden alınarak bir araya getirilmiştir. Yararlanılan kaynaklar ve avokado odununun kimyasal ve morfolojik yönden orman endüstrisinde kullanılan okaliptüs, titrek kavak, ak meşe ve söğüt gibi yaygın kullanılan ağaçların odunları ile benzer özellikte olduğu tespit edilmiştir. Ülkemizde yapraklı ağaç ormanları karışık meşçerelerden oluşmaktadır. Yapacak odun dışında kalan kısım tasnif edilmeden karışık olarak ster yapılarak satılır. Kağıt fabrikaları tarafından satın alınan yapraklı ağaç odunları kimyasal yöntemlerle kağıt hamuru üretiminde yongalanarak karışık halde pişirilmektedir. Bu kati bir zorunluluktan değil, tür tasnifinin ekonomik olmadığından kaynaklanmaktadır. Zaman içerisinde fabrikalarda deneyim kazanılarak hangi türlerin bir arada pişirilmesinin uygun olacağı belirlenmekte ve hazırlanan pişirme cetvelleri sayesinde önemli bir sorun yaşanmamaktadır. Aynı türden meyve bahçelerinin budama artıkları ve/veya kesilen yaşı ıireylerden elde edilen odun miktarı tek başına bir kağıt fabrikasının hammadde ihtiyacını karşılamayabilir. Bu nedenle yapraklı ağaç odunları ve/veya diğer değişik meyve ağacı odunlarının kağıt hamuru üretiminde bir arada pişirilmesi gerekebilir. Değişik meyve türlerinin kimyasal ve morfolojik özelliklerinin önceden bilinmesi karışık pişirilmeleri durumunda hangi türlerin bir arada kullanılabileceği hakkında ön bilgi verecektir. Özellikle lignin oranı çok yüksek türlerle düşük olanlar bir arada kullanılırsa, düşük olana göre pişirme şartı ayarı yapılması durumunda yüksek olan yongalar liflenmez bu durumda pişmemiş yongalar nedeni ile veya lignin oranı düşük yongaların aşırı pişmesi ile elenmiş verimi düşer. Öngörülen bu olumsuzluklarla karşılaşmamak için bu literatür bilgilerinin ortaya konulması önemlidir. Hammadde arzı değerlendirilerek Tablo 4 deki ağaç türü odunlarının lignin oranı birbirine yakın olanların bir arada pişirmeleri uygun olabilir. Ayrıca, bu çalışmalar sayesinde morfolojik özellikleri birbirine benzer olan türlerin de bir arada pişirilme imkanı doğacaktır. Bu yolla farklı ağaç türlerinin odunlarından benzer özelliklerde hamur elde etme imkanı olacaktır. Bundan sonra yapılan çalışmalarda meyve ağaçlarının kağıt hamuru üretiminde pişirme tablolarının oluşturulmasının kullanıcılar için faydalı olacağı kanaatindeyiz.

\section{Teşekkür}

Fotoğrafların çekimindeki katkılarından dolayı; Prof. Dr. Barbaros YAMAN'a teşekkür ederiz.

\section{Kaynaklar}

1. Akgül, M., Akça, M. (2014). İğde ağacı odunu (Elaeagnus angustifolia L.) ve kabuğunun kimyasal analizi. II. Ulusal Akdeniz Orman ve Çevre Sempozyumu Bildiri Kitabı, 568-573, 22-24 Ekim 2014, Isparta.

2. Akgül, M., Uner, B., Çamlıbel, O., Ayata, Ü. (2017). Manufacture of Medium Density of Fiberboard (MDF) Panels from Agribased Lignocellulosic Biomass, Wood Research, 62(4), 615-624.

3. As, N., Koç, K. H., Doğu, A. D., Atik, C., Aksu, B., Erdinler, E. S. (2001). Türkiye'de Yetişen Endüstriyel Öneme Sahip Ağaçların Anatomik, Fiziksel, Mekanik ve Kimyasal Özellikleri, İstanbul Üniversitesi, Orman Fakültesi Dergisi, 51(1), 71-88.

4. Bayram, S., Arslan, M. A., Turgutoğlu, E. (2006). Türkiye’de Avokado Yetiştiriciliğinin Gelişsimi, Önemi ve Önerilen Bazı Çeşitler, DERIM, Batı Akdeniz Tarımsal Araştırma Enstitüsü, TAGEM JOURNALS, 23 (2), 1-13.

5. Casey, J. P. (1960). Pulp and Paper Chemistry and Chemical Technology, Vol. 1, Second Edition. Wiley Interscience Publisher Inc., New York, 580 pages.

6. Çavuş, V. (2020). Determination of Some Physical and Mechanical Properties of Apricot Wood (Prunus armeniaca L.), Bartın Orman Fakültesi Dergisi, 22 (2): 457-464, DOI: 10.24011/barofd.729707

7. Demirkol, A. (2001). Bazı Avokado Çeşitlerinin Antalya Koşullarında Gösterdiği Ağaç Özellikleri ve İklim Koşullarından Etkilenme Durumları, $B A H C ̧ E$, Atatürk Bahçe Kültürleri Merkez Araştırma Enstitüsü Müdürlüğü, 30 (1), 95 - 07, ISSN 1300-8943,

8. Dyjakon, A., den Boe,r J., Gebresenbet, G., Bosona, T., Adamczyk, F., (2020). Economic analysis of the collection and transportation of pruned branches from orchards for energy production, DREWNO, Vol:63,125-140.

9. Eroğlu, H. (1990). Kă̆ıt Hamuru ve Kağıt Fiziği, Karadeniz Teknik Üniversitesi, 2.Bask1, Yayın No:90, Trabzon. $623 \mathrm{~s}$

10. Eroğlu, H. (2003). Kağıt Hamuru ve Kağıt Fiziği Ders Notlarl, ZKÜ BOF Üniversite Yayın No:27, Fakülte Yayin No:13, 144s.

11. Fuentes-Talavera, F.J., Silva-Guzmán, J.A., Rodríguez-Anda, R., Lomelí-Ramírez, M.G., SanjuánDueñas y H.G. (2011). Richter Strength properties and natural durability of Avocado (Persea americana 
Mill.) branch wood, Madera y Bosques 17(1), 37-47. (F.J. Fuentes-Talavera1, J.A. Silva-Guzmán, R. Rodríguez-Anda, M.G. Lomelí-Ramírez, R. Sanjuán-Dueñas y H.G. Richter)

12. Gencer, A. (2015). The utilization of Kiwi (Actinidia deliciosa) pruning waste for kraft paper production and the effect of the bark on paper properties. DREWNO 58(194) DOI: 10.12841/wood.1644-3985.084.08

13. Gençer, A., Aksoy, H. (2017). Yabani kızılcık (Cornus australis L.) odunundan kâğıt üretimi ve kabuğun kâğıt özelliklerine etkisi. Artvin Çoruh Üniversitesi Orman Fakültesi Dergisi, 18(2), 186-191.

14. Gençer, A., Gül Türkmen, H. (2016). Yabani Kiraz Diri Odunu ve Öz Odunundan Kağıt Üretim Şartlarının Belirlenmesi, Bartın Orman Fakültesi Dergisi 18(1), 23-31.

15. Gençer, A., Özgül, U. (2016). Utilization of common hazelnut (Corylus avellana L.) prunings for pulp production. Drvna industrija 67(2), 157-162.

16. Gençer, A., Özgül, U. (2015). Yaygın findık (Corylus avellana L.) odunundan soda yöntemi ile kâğıt hamuru üretim parametrelerinin belirlenmesi. Turkish Journal of Forestry, 16(2), 159-163.

17. Gençer, A., Şirin, G., Gül, H., Özgül, U. (2013). Determination of the Product Conditions of Pulp and Paper From White Mulberry (Morus alba L.) by Kraft Method, Bartın Orman Fakültesi Dergisi, Cilt: 15, Say1: 1-2, ISSN: 1302-0943, EISSN: 1308-5875.

18. Gençer., A., Özgül, U., Onat, S. M., Gündüz, G., Yaman, B., Yazıcı, H. (2018). Chemical and morphological properties of apricot wood (Prunus armeniaca L.) and fruit endocarp. Bartın Orman Fakültesi Dergisi 20(2), 205-209.

19. Gulsoy, S. K., Tufek, S. (2013). Effect of mixing ratio of Pinus pinaster and Populus tremula on kraft pulp and paper properties, Ind. Eng. Chem. Res. 52(6), 2304-2308.

20. Güler, C., Şahin, H.İ., Çiçek, E. (2012). Farklı Dikim Aralıklarında Yetişen Dar Yapraklı Dişbudak (Fraxinus angustifolia) Odunlarının Bazı Anatomik ve Morfolojik Özellikleri, Süleyman Demirel Üniversitesi Orman Fakültesi Dergisi, 13 (1), 35-40.

21. Gülsoy S K, Kılıç Pekgözlü A., Aktaş, A. C. (2015). Utilization of the pomegranate tree (Punica granatum L.) in the paper industry, Turk J Agric For 39: 295-299 (C) TÜBİTAK doi:10.3906/tar-1404-105.

22. Gülsoy, S K., Eroğlu, H., Merev, N. (2005). Chemical and Wood Anatomical Properties of Tumorous Wood in a Turkish White Oak (Quercusrobur subsp. robur) IAWA Journal, Vol. 26 (4), 2005: 469-476

23. Gündüz, G., Yıldırım, N., Şirin, G. Onat, S. M. (2009). Ak Dut Ağacının Anatomik, Kimyasal, Fiziksel ve Mekanik Özellikleri, Düzce Üniversitesi Ormancılık Dergisi, 5(1), 131-149.

24. Gürboy B., Özden, Ö. (1994). E. camaldulensis ve E. grandis Odununun Hacim-Ağırlık Değerleri Ve Lif Morfolojisi, İstanbul Üniversitesi Orman Fakültesi Dergisi, Seri A, Cilt volüm 44, sayı 1, 101-109

25. IAWA Committee (1989). IAWA list of microscopic features for hardwood identification IAWA Bulletin n.s., 10, 219-332.

26. Kesik, H. İ., Kaymakçı, A., Olgun, Ç., Çağatay, K., Tor, Ö. (2017). Portakal (Citrus x sinensis (L.) Osbeck) Odununun Fiziksel, Kimyasal ve Mekanik Özellikleri, Uluslararası Taşköprü Pompeiopolis Bilim Kültür Sanat Araştırmalar Sempozyumu, 1627-1633, 10-12 Nisan, 2017.

27. Kırcı, H. (2000). Kâğıt Hamuru Endüstrisi Ders Notları. Karadeniz Teknik Üniversitesi Orman Fakültesi, Ders Notlar1 Yayın No:63, Trabzon, 274s.

28. Merev, N. (1998). Odun Anatomisi Cilt 1A. Doğu Karadeniz Bölgesindeki Doğal Angiospermae Taksonlarının Odun Anatomisi. Genel Yayın NO: 189, Fakülte Yayın No:. 27, KTÜ, Trabzon. 396 sayfa.

29. Merev, N. (2003). Odun Anatomisi. KTÜ Orman Fakültesi, Genel Yayın No:209, Fakülte Yayın No:31, Trabzon, 246 sayfa.

30. Nemli, G., Kırcı, H., Serdar, B., Ay, N. (2003). Suitability of kiwi (Actinidia sinensis Planch.) prunings for particleboard manufacturing, Industrial Crops and Products, 17, 39-46.

31. Odabaş Serin, Z., Ateş, N., Cavunt, A. (2017). Biberiye (Rosmarinus officinalis L.) saplarının kağıt hamuru ve kağıt üretimine uygunluğunun değerlendirilmesi, Türkiye Ormancllık Dergisi, 18(2), 155-159.

32. Odabaş Serin, Z., Kılıç Penezoğlu, M. (2020b). Aydın ve Kahramanmaraş’ta Yetişen Zeytin (Olea europaea L.) Odunun Bazı Özellikleri, Turkish Journal of Forest Science, 4(2), 396-407.

33. OdabaşSerin, Z., Kılıç Penezoğlu, M. (2020a). İncir (Ficus carica) Odunun Kimyasal, Fiziksel ve Morfolojik Özellikleri. Avrupa Bilim ve Teknoloji Dergisi, 19, 843-849.

34. Özcan, K., Dönmez, İ.E. (2018). Isparta Güneykent bölgesinde yetişen gül odununun (Rosa damascena Mill.) kimyasal bileşimi ve lif özellikleri, Türkiye Ormancılık Dergisi, 19(4), 442-446.

35. Rowell, R.M. (2013). Handbook of Wood Chemistry and Wood Composites. Second Edition, Ed. Rowell, R.M., Petterson R., Tshabalala, M.A., CRC press, USA. 33-74

36. Rydholm, S. A. (1965). Pulping processes. Vol. 1, 1st Ed., Interscience Publishers, California, 1269 pages.

37. Şahin, H.T., Arslan, M.B. (2013). Properties of Orchard Pruning and Suitability for Composite Production, Science and Engineering of Composite Materials, 20(4), 337-342.

38. TAPPI T 203 cm-99 (1999). Alpha-, beta- and gamma-cellulose in pulp. Atlanta, GA, USA.

39. TAPPI T 204 cm-97 (1997). Solvent extractives of wood and pulp. Atlanta, GA, USA.

40. TAPPI T 207 cm-99 (1999). Water solubility of wood and pulp. Tappi Press, Atlanta, GA, USA. 
41. TAPPI T 212om-12 (2012). One percent sodium hydroxide solubility of wood and pulp. Tappi Press, Atlanta, GA, USA.

42. TAPPI T 222 om-02 (2002). Acid-insoluble lignin in wood and pulp. Tappi Press, Atlanta, GA, USA.

43. TAPPI T 264 cm-07 (2007). Preparation of wood for chemical analysis, Tappi Press, Atlanta, GA, USA.

44. Tirak Hizal, K., Erdin, N. (2016). Radial Variation of Annual Ring Width and Fiber Dimensions from Natural and Plantation Trees of Alder (Alnus glutinosa L. Gaertner) Wood, Düzce Üniversitesi Orman Fakültesi Ormancllı Dergisi, 12(2),1-12.

45. Topaloğlu, E., Öztürk, M., Ustaömer, D., Serdar, B. (2019). Doğu Karadeniz Bölgesi’ndeki Bazı Meyve Ağaçlarının Odun Anatomisi Özellikleri ve Kağıt Üretimi açısından Değerlendirilmesi, Ormancılık Araştırma Dergisi, 6 (2), 142-151.

46. Topaloğlu, E., Ustaömer, D. (2020). Bazı Meyve Ağaçları Gövde Odunlarının Fiziksel, Mekanik ve Yüzey Özelliklerinin Araştırılması, Düzce Üniversitesi Bilim ve Teknoloji Dergisi, 8(1), 123-136.

47. Tutuş, A., Çiçekler, M., Özdemir, F., Yılmaz, U. (2014). Kahramanmaraş koşullarında yetişen Trabzon hurma ağacı (Diospyros kaki)'nin kağıt hamuru ve kağıt üretiminde değerlendirilmesi, II. Ulusal Akdeniz. Orman ve Çevre Sempozyumu, 22-24 Ekim 2014, Isparta, s.775-784.

48. Tutuş, A., Çiçekler, M., Ayaz, A. (2016a). Kayısı (Prunus armeniaca L.) odunu yongalarının kağıt hamuru ve kağıt üretiminde değerlendirilmesi, Türkiye Ormancılık Dergisi, 17(1), 61-67.

49. Tutuş, A., Çiçekler, M., Küçükbey, N. (2016b). Pulp and paper production from bitter orange (Citrus aurantium L.) woods with sodaaq method. Kastamonu University Journal of Forestry Faculty, 16(1):14-18.

50. Tutuş, A., Çiçekler, M., Bektaş, İ., Odabaş-Serin, Z., Özdemir, F. (2018). Investigation of the chemical morphological properties of lamas lemon tree wood growing in the Erdemli, Proceedings Book of International Erdemli Symposium, 19-21 April 2018, 894- 899, Erdemli-Mersin, Turkey.

51. Tümen, İ. (1999). Armut Ağacının Fiziksel, Anatomik ve Kimyasal Özellikleri.Yüksek Lisans Tezi (yayımlanmamış) ZKÜ Fen Bilimleri Enstitüsü, Orman Endüstri Mühendisliği Anabilim Dalı, Zonguldak, $84 \mathrm{~s}$.

52. Vargas, R., J.R. Sanjuán, D., J.A. Silva G., J. Rivera P., F.J. Fuentes T., Richter, H.G. (2006). Properties of bleached pulp sheets of avocado wood (Persea americana Mill.) pulped by Kraft and Soda processes, Madera y Bosques 12(1), 29-36.

53. Walia, Y.K. (2013). Chemical and Physical analysis of Morus nigra (Black Mulberry) for its pulpability, Asian J. of Adv. Basic Sci.: 1(1), 40-44.

54. Wise, L.E., Jahn, E.C. (1952). Wood Chemistry. 2nd Edition, Vol 1-2, Reinhold Publication Co. New York, U.S.A, 1330 pages.

55. Yaman, B. (2002). Türkiye'nin Euro-Siberian (Euxine) Bolgesi’nde Doğal Olarak Yetişen Yabani Kiraz (Cerasus aveum (L.) Moench)'ın Morfolojik, Anatomik ve Palinolojik Özellikleri, Doktora Tezi (yayımlanmamış), ZKÜ Fen Bilimleri Enstitüsü, Orman Mühendisliği Anabilim Dalı, Zonguldak, 133 s.

56. Yaman, B. (2014). Anatomical differences between stem and branch wood of Ficus carica L. subsp. carica. Modern Phytomorphology.

57. Yaman, B., Gençer, A. (2005). Trabzon Koşullarında Yetiştirilen Kivi (Actinidia deliciosa (A. Chev.) C. F. Liang \& A. R. Ferguson)'nin Lif Morfolojisi, Süleyman Demirel Üniversitesi Orman Fakültesi Dergisi Seri: A, Say1: 2, 149-155.

58. Zentymer, G.A. (1987). Avocados around the World. Avocado Society Yearbook, 71: 63-77. 